\title{
Correction to: Role of HMGB1 in TNF-a Combined with Z-VAD-fmk-Induced L929 Cells Necroptosis
}

\author{
Zhao Lei ${ }^{1} \cdot$ Can $\mathrm{Yu}^{2} \cdot \mathrm{Xia} \mathrm{Li}^{3} \cdot \mathrm{Li}-\mathrm{Hua} \mathrm{Huang}{ }^{4} \cdot \mathrm{Zhi}^{-Q i a n g ~} \mathrm{Li}^{1} \cdot$ Hong-Wei Zhu${ }^{1}$. \\ Duo Han ${ }^{1} \cdot$ Hui Huang ${ }^{1} \cdot \mathrm{Xiao} \mathrm{Yu}^{1}{ }^{\mathbb{D}}$
}

Published online: 3 September 2021

(c) Springer Science+Business Media, LLC, part of Springer Nature 2021

\section{Correction to: Biochemical Genetics https://doi.org/10.1007/s10528-021-10107-1}

The original version of this article unfortunately contained a mistake. In this article, the order that the authors appeared in the author list was incorrect. The order of the authors has now been corrected.

One of the Funding information was missing from this article and should have read 'Hunan Natural Science Foundation Youth Fund Project (No. 2021JJ40952)'.

The original article has been corrected.

Publisher's Note Springer Nature remains neutral with regard to jurisdictional claims in published maps and institutional affiliations.

The original article can be found online at https://doi.org/10.1007/s10528-021-10107-1.

Xiao Yu

yuxiaoyx90@163.com

1 Departments of Hepatopancreatobiliary Surgery, Third Xiangya Hospital, Central South University, No. 138 Tongzipo Road, Yuelu District, Changsha 410013, Hunan Province, People's Republic of China

2 Departments of Intensive Care Unit, Third Xiangya Hospital, Central South University, Changsha 410013, Hunan Province, People's Republic of China

3 Departments of Endocrinology, Third Xiangya Hospital, Central South University, Changsha 410013, Hunan Province, People's Republic of China

4 Center for Medical Experiments, Third Xiangya Hospital, Central South University, Changsha 410013, Hunan Province, People's Republic of China 